\title{
Bronchoalveolar lavage as a tool for evaluation of cellular alteration during Aelurostrongylus abstrusus infection in cats ${ }^{1}$
}

\author{
Vitor M. Ribeiro², Joziana M.P. Barçante ${ }^{3 *}$, Déborah Negrão-Correa ${ }^{4}$, Thales A. \\ Barçante $^{3,5}$, André Klein ${ }^{6}$ and Walter S. Lima ${ }^{4}$
}

\begin{abstract}
Ribeiro V.M., Barçante J.M.P., Negrão-Correa D., Barçante T.A., Klein A. \& Lima W.S. 2014. Bronchoalveolar lavage as a tool for evaluation of cellular alteration during Aelurostrongylus abstrusus infection in cats. Pesquisa Veterinária Brasileira 34(10):990995. Setor de Preventiva, Departamento de Medicina Veterinária, Universidade Federal de Lavras, Campus Universitário, Lavras, MG 37200-000, Brazil. E-mail: joziana@dmv.ufla.br

Bronchoalveolar lavage (BAL) is a procedure that retrieves cells and other elements from the lungs for evaluation, which helps in the diagnosis of pulmonary diseases. The aim of this study was to perform this procedure for cellular analysis of BAL fluid alterations during experimental infection with Aelurostrongylus abstrusus in cats. Fourteen cats were individually inoculated with 800 third stage larvae of $A$. abstrusus and five non-infected cats lined as a control group. The BAL procedure was performed through the use of an endotracheal tube on the nineteen cats with a mean age of 18 months, on $0,30,60,90$, 120, 180 and 270 days after infection. Absolute cell counts in the infected cats revealed that alveolar macrophages and eosinophils were the predominant cells following infection. This study shows that the technique allows us to retrieve cells and first stage larvae what provides information about the inflammatory process caused by aelurostrongylosis.
\end{abstract}

INDEX TERMS: Cytology, immunology, Aelurostrongylus abstrusus, aelurostrongylosis, cats.

RESUMO.- [Lavado broncoalveolar como ferramenta para avaliação de alterações celulares durante a infecção por Aelurostrongylus abstrusus em gatos.] 0 lavado broncoalveolar (LBA) é um procedimento que permite a recuperação de células e outros elementos pulmonares para avaliação, auxiliando no diagnóstico de doenças pulmonares. 0 objetivo do presente trabalho foi realizar este procedimento para avaliação das células presentes no fluido broncoalveolar na infecção experimental por Aelurostron-

\footnotetext{
${ }^{1}$ Received on November 20, 2013.

Accepted for publication on June 14, 2014

${ }^{2}$ Curso de Medicina Veterinária, Pontifícia Universidade Católica de Minas Gerais (PUCMinas), Campus Betim, Rua do Rosário 1081, Betim, MG 32604-115, Brazil.

${ }^{3}$ Departamento de Medicina Veterinária (Preventiva), Universidade Federal de Lavras, MG 37200-000, Brazil. *Corresponding author: joziana@ dmv.ufla.br

${ }^{4}$ Departamento de Parasitologia, Instituto de Ciências Biológicas (ICB), Universidade Federal de Minas Gerais (UFMG), Av. Presidente Antônio Carlos 6627, São Luiz, Belo Horizonte, MG 37270-901, Brazil.

${ }^{5}$ Curso de Medicina Veterinária, PUC Minas, Campus Poços de Caldas, Av. Francis Cletus Cox 1661, Country Club, Poços de Caldas, MG 37701355, Brazil.

${ }^{6}$ Departamento de Farmacologia, ICB-UFMG, Av. Presidente Antônio Carlos 6627, São Luiz, Belo Horizonte, MG 37270-901.
}

gylus abstrusus em gatos. Quatorze animais foram individualmente inoculados com 800 larvas de terceiro estádio de $A$. abstrusus, enquanto cinco animais não infectados foram mantidos como grupo controle. O LBA foi realizado com uso de um tubo endotraqueal em todos os 19 animais com média de idade de 18 meses, nos dias nos dias 0,30 , $60,90,120,180$ e 270 após infecção. A contagem absoluta de células dos animais infectados revelou que macrófagos alveolares e eosinófilos constituíram os tipos celulares predominantes durante todo o período de infecção. Os resultados deste trabalho demonstram que a técnica permite recuperar células e larvas de primeiro estádio de $A$. abstrusus, fornecendo informações importantes sobre o processo inflamatório causado na aelurostrongilose.

TERMOS DE INDEXAÇÃO: Citologia, imunologia, Aelurostrongylus abstrusus, aelurostrongilose, felinos.

\section{INTRODUCTION}

Parasitic nematode infection of the respiratory tract in dogs and cats has received increasing attention in recent years, with the proposal of examination measures for the diagnosis of lungworm infection (Knaus et al. 2011). The nematode Aelurostrongylus abstrusus (Soulsby 1987, Pennisi et al. 
1994) of the family Protostrongylidae has worldwide distribution, and parasitizes the lung parenchyma, pulmonary artery and its branches in both domestic and wild cats.

Infection in cats results from the ingestion of an infected intermediate host, such as snails and slugs, or a paratenic host, such as frogs, lizards, birds or rodents. Third-stage larvae (L3) invade the gastrointestinal mucosa and migrate through the blood vessels to the lungs, where they develop to sexual maturity. Adult individuals of $A$. abstrusus are found deep in terminal bronchioles and alveolar ducts of the definitive host, where females deposit their eggs. First-stage larvae (L1) are actively transported from the terminal bronchioles toward the upper respiratory tract through the coughing mechanism in the host. These larvae are then swallowed and excreted into the environment with the feces, where they can potentially infect intermediate hosts (Soulsby 1987).

The clinical signs of infection vary depending on the nature of the respiratory problem. While aelurostrongylosis is subclinical in most infected cats (Traversa et al. 2008a,b), mild to severe coughing, sneezing, mucopurulent nasal discharge, dyspnea and hydrothorax may be observed (Ribeiro \& Lima 2001, Traversa et al. 2008a). Infection may lead to pneumonia, pleural effusion, pyothorax and even death in the absence of therapeutic intervention (Gathumbi et al. 1991, Traversa \& Guglielmini 2008, Traversa et al. 2008a, Knaus et al. 2011).

A fecal examination is an important method for the diagnosis of aelurostrongylosis (Willard et al. 1988). The current diagnostic technique is the modified Baermann method (Barçante et al. 2003), which is used to detect first-stage larvae in feces (Willard et al. 1988). However, this procedure lacks sensitivity due to fact that L1 shedding is not continuous. Infected animals exhibit an intermittent pattern of larvae elimination through the feces, which often leads to a false-negative result when the Baermann method alone is used (Ribeiro \& Lima 2001). Infected cats may harbor adult worms in their lungs for several years without excreting L1 through the feces. In such cases, fecal analysis is negative and does not allow the confirmation of the diagnosis by means of parasitological exams. Radiography, fine-needle biopsy, tracheal lavage, computed tomography and molecular diagnostic methods have also been used for the diagnosis of aelurostrongylosis in cats (Losonsky et al. 1983, Payo-Puente et al. 2005, Traversa et al. 2008a,b, Dürr 2009, Lacorcia et al. 2009). Alternative methods such as bronchoalveolar lavage are laborious, but it may be a good tool for differential diagnosis in cats presenting with respiratory symptoms (Barutzki \& Schaper 2013).

Bronchoalveolar lavage fluid (BALF) is considered a safe procedure performed on dogs and cats to collect samples from the distal portion of the lungs (Clercx \& Peeters 2007; Basso et al. 2008; Hawkins et al. 2008). This procedure has been used to diagnose viral, bacterial, protozoal and fungal infections as well as tumors and other diseases (Hawkins 1992). Moreover, the cytological and microbiological evaluation of BALF can be used as an auxiliary tool to characterize pulmonary diseases in dogs and cats (Hawkins et al. 2008).
The aim of the present experimental study was to test BALF as a tool for the retrieval of cells and first stage larvae of $A$. abstrusus for cytological evaluation to provide information about inflammatory processes caused by the parasite.

\section{MATERIALS AND METHODS}

Parasite source. The strain of Aelurostrongylus abstrusus used in the experiments was isolated from the feces of a domestic cat. The nematode has been maintained by means of serial infections of domestic cats and aquatic snails (Biomphalaria glabrata) at the Laboratory of Veterinary Helminthology, Department of Parasitology, Universidade Federal de Minas Gerais (UFMG), Brazil.

All procedures were performed by a veterinarian and the experimentation protocols were carried out in compliance with the Ethical Principles in Animal Experimentation adopted by Brazilian College of Animal Experimentation (COBEA) and the Ethics Committee on Animal Experimentation of the Federal University of Minas Gerais (CETEA/UFMG/№060/2003).

Animals. Nineteen female mongrel cats (Felis cattus domesticus) with a mean age 18 months were used in the experiment. The cats were born and bred in the breeding facilities of the UFMG Department of Parasitology and were free of A. abstrusus infection. The animals were vaccinated against feline panleukopenia, feline herpesvirus I and feline calicivirus (Eurifel- PHC -Merial), caged individually and provided with commercial cat food (Hill's Science Diet Maintenance) and water ad libitum. Clinical exams were performed 30 days prior to the experiment. Following the manufacturer's instructions, the cats were treated with a subcutaneous injection of ivermectin $(400 \mu \mathrm{g} / \mathrm{kg})$ to eliminate any worm infections caused by common feline parasites. Four fecal exams were performed at seven-day intervals using the Baermann's fecal sedimentation method to verify that the animals were free of helminth infection following treatment.

Parasitic infection. First-stage larvae (L1) of A. abstrusus were isolated from the feces of an experimentally infected cat using a Baermann apparatus, followed by filtration on filter paper, as described by Barçante et al. (2003). Biomphalaria glabrata snails were individually exposed to $400 \mathrm{~L} 1$ of A. abstrusus for 24 $\mathrm{h}$ in $2 \mathrm{~mL}$ of de-chlorinated water. Thirty days following infection, third-stage larvae (L3) were recovered, as described by Barçante (2004), and counted under a stereomicroscope.

To perform the infection procedure, the cats were pre-medicated with subcutaneous injection of atropine sulfate ${ }^{7}(0.044 \mathrm{mg} /$ $\mathrm{kg}$ of body weight). After $15 \mathrm{~min}$, anesthesia was administered through an intramuscular injection of acepromazine ${ }^{8}(0.1 \mathrm{mg} / \mathrm{kg}$ of body weight) and ketamine ${ }^{9}(5 \mathrm{mg} / \mathrm{kg}$ of body weight). Fourteen animals were individually inoculated with $800 \mathrm{~L} 3$ of $A$. abstrusus. For such, the larvae were suspended in $1.5 \mathrm{~mL}$ of PBS and administrated through a stomach tube. Five animals received $1.5 \mathrm{~mL}$ of PBS containing an extract of non-infected snails as the non-infected control group.

From 0 to 60 days post-infection (DPI), fecal samples were collected daily from the cage of each animal in the infected group and submitted to a modified Baermann apparatus to recover L1 to determine the prepatent period, after which feces were collected monthly.

Bronchoalveolar lavage. BALF was performed on day 0,30 , $60,90,120,180$ and 270 . For such, the cats were pre-medicated and anesthetized as described above and positioned in dorsal re-

\footnotetext{
${ }^{7}$ Atropina, Farmagrícola S.A. Import and Export, Mairiporam, SP, Brazil.

${ }^{8}$ Acepran 1\%, Fort Dodge, Campinas, SP, Brazil.

${ }^{9}$ Francotar, Fort Dodge.
} 
cumbency. BALF was performed using an endotracheal tube reaching the carina $(3.5 \mathrm{~mm})$. The cuff of the tube was expanded and a sterile urinary catheter was inserted to the level of the carina. BALF was harvested by injecting $2 \mathrm{~mL} / \mathrm{kg}$ of body weight of warm $\left(38^{\circ} \mathrm{C}\right)$ sterile phosphate-buffered saline (PBS: $136 \mathrm{mM} \mathrm{NaCl}$, $2 \mathrm{mM} \mathrm{KCl}, 8 \mathrm{mM} \mathrm{Na}_{2} \mathrm{HPO}_{4}, 10 \mathrm{mM} \mathrm{KH}_{2} \mathrm{PO}_{4}, \mathrm{pH} 7.4$ ) with the addition of $5 \%$ fetal calf serum (Nutricell, Campinas, SP, Brazil). The total volume was fractionated and applied in aliquots of $3 \mathrm{~mL}$ to avoid overloading the lung fluid. The animals were given oxygen therapy before and five min after the procedure.

Parasitic evaluation from BALF. The final volume of the bronchoalveolar fluid (BALF) recovered was quantified. To evaluate the use of this fluid as a diagnostic procedure, three aliquots of $10 \mu \mathrm{L}$ were retrieved from the BALF of each animal and examined under a stereomicroscope for the presence of L1.

Cellular evaluation of BALF. The BALF of each animal was diluted (1:1) with PBS containing $1 \mathrm{mM}$ of dithiothreitol (DTT) and kept in a water bath for $30 \mathrm{~min}$ at $37^{\circ} \mathrm{C}$ to dissolve the mucus. The viability of the cell population was estimated from total BALF diluted (1/10) in RPMI-1640 medium ${ }^{10}$ containing 0.4\% Trypan Blue (Sigma) for the determination of membrane-damaged cells. Blue cells were counted in a Neubauer chamber and assumed as unviable. For the quantification of recovered cells, the BALF was separated from the supernatant and cells through centrifugation at $200 \mathrm{~g}$ for $10 \mathrm{~min}$ at $4^{\circ} \mathrm{C}$. The cell pellet was washed twice with a RPMI-1640 medium and re-suspended in complete RPMI-1640 (with the addition of $10 \%$ fetal calf serum).

Total cell counts were determined in a Neubauer chamber. For differential cell counts, aliquots were removed for a final concentration of $1 \times 10^{5}$ cells $/ \mathrm{mL}$ and differential cell counts were performed on cytospin ${ }^{11}$ preparations using standard morphological criteria to identify cell types. Two hundred cells were counted per preparation and the results were expressed as the number of cells per $\mathrm{mL}$.

Statistical analysis. The data were expressed as mean and standard deviation values. One-way analysis of variance (ANOVA) and the Student-Newman-Keuls method were used for the statistical analysis, with the level of significance set to $5 \%(\mathrm{p}<0.05)$.

\section{RESULTS}

The clinical signs of cough and moist crackling upon auscultation observed in the cats after bronchoalveolar lavage cleared up spontaneously within $24 \mathrm{~h}$ following the lavage procedure in both the control and infected groups. There were no anesthetic or procedure-related complications.

Based on the feces examination, the prepatent period for cats experimentally infected with Aelurostrongylus abstrusus ranged from 35 to 48 days (mean: $38.78 \pm 4.28$ ). Figure 1 displays the mean larval output per month, expressed as logarithmic values [log. (lpg+1)]. Peak larval output per gram of feces was observed at 60 and 120 DPI. (Fig.1)

Active L1 A. abstrusus were recovered from the BALF of three infected cats from 60 to $120 \mathrm{DPI}$, which could be related to the amount of larvae passing from the lungs to the gut in this period (Fig.2). The specimens measured from 270 to $330 \mathrm{~mm}$ in length and 17 to $19 \mathrm{~mm}$ in width and had a characteristic cephalic button and tail undulation with a dorsal notch (Lima et al. 1985).

No statistically significant differences were found in the volume percentage of the fluid recovered from the lavage procedure in the cats infected with A. abstrusus and the five

\footnotetext{
${ }^{10}$ Gibco, Grand Island, NY, USA.

${ }^{11}$ Cytospin 2, Southern Instruments, UK.
}

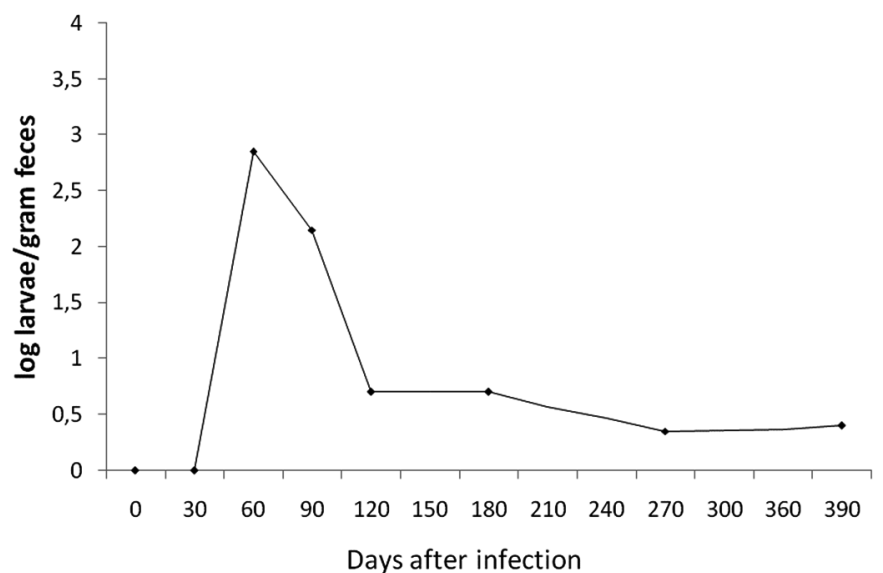

Fig.1. Mean larval output per gram of feces of 14 cats infected with 800 infective larvae of Aelurostrongylus abstrusus per kilogram of body weight. Mean expressed as logarithmic values [log. $(\operatorname{lpg}+1)]$.

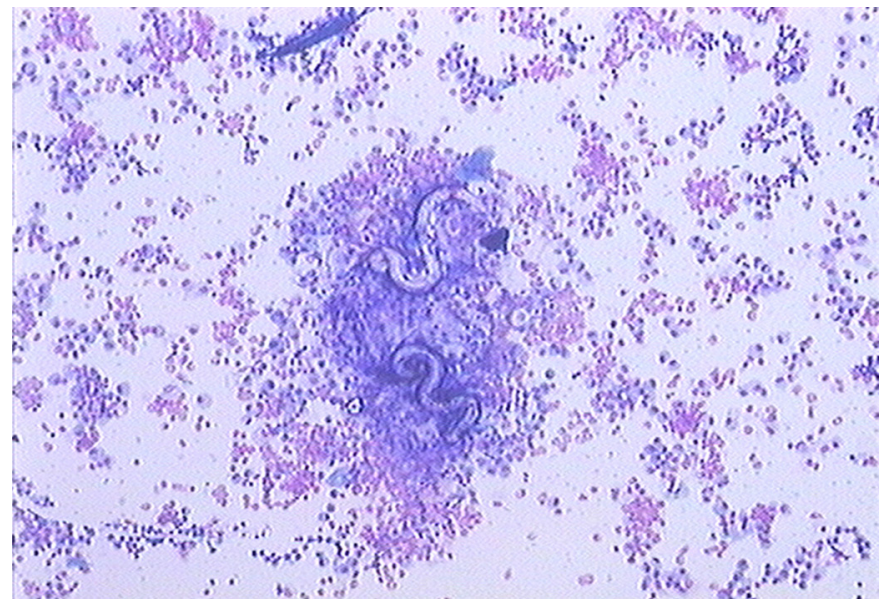

Fig.2. Two first-stage larvae of Aelurostrongylus abstrusus in a direct smear of bronchoalveolar lavage fluid from a cat 60 days post-infection with 800 third-stage larvae. Obj.40x.

non-infected cats ( $p>0.05)$. Mucus and foam were observed in the BALF in both groups. However, the infected animals had a greater amount of mucus and phlegm in comparison to the non-infected animals.

No significant differences in total mean cell count or differential cell counts were found in the non-infected animals at the different evaluation times ( $p>0.05)$. Significant differences were found in the total mean and differential cell counts between the infected and non-infected cats at all evaluation times following infection. Moreover, notable variations in total and relative differential cell counts were found in the infected cats throughout the different evaluations. From 30 to $270 \mathrm{DPI}$, the number of total leukocytes recovered in the BALF of infected animals was significantly higher in comparison to the control animals $(\mathrm{p}<0.05)$. At 90 and $120 \mathrm{DPI}$, the highest total cell counts occurred in the infected group (period of greatest larval production) (Fig.3).

Absolute counts in the infected animals revealed that alveolar macrophages and eosinophils were the predominant cells following infection. The macrophage count was significantly increased at 90 DPI in comparison to the non- 


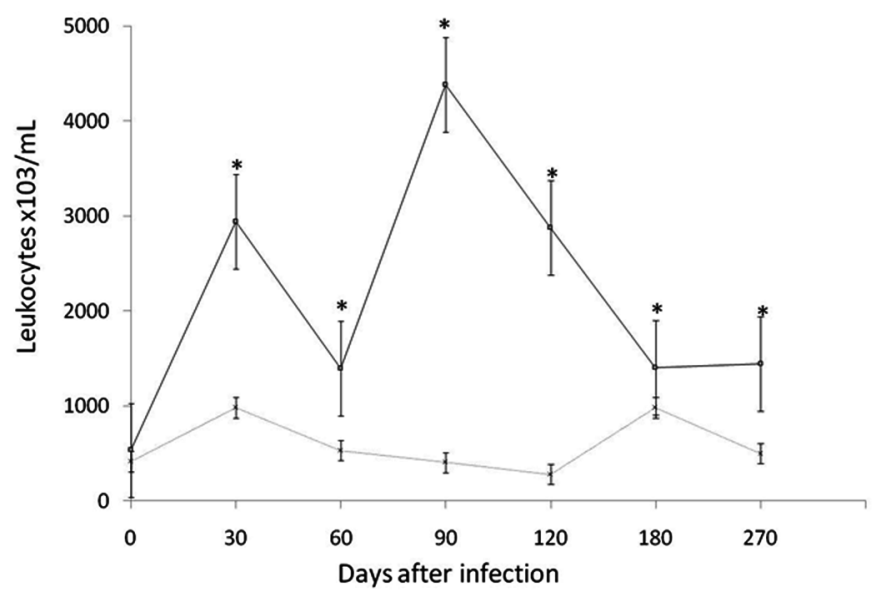

Fig.3. Total leukocytes in bronchoalveolar lavage from 14 cats infected with 800 infective larvae of Aelurostrongylus abstrusus per kilogram of body weight (infected group = bold line) and from five cats free of any helminthic infection (control group = thin line). The asterisk indicates a significant statistical difference $(p<0.05)$.
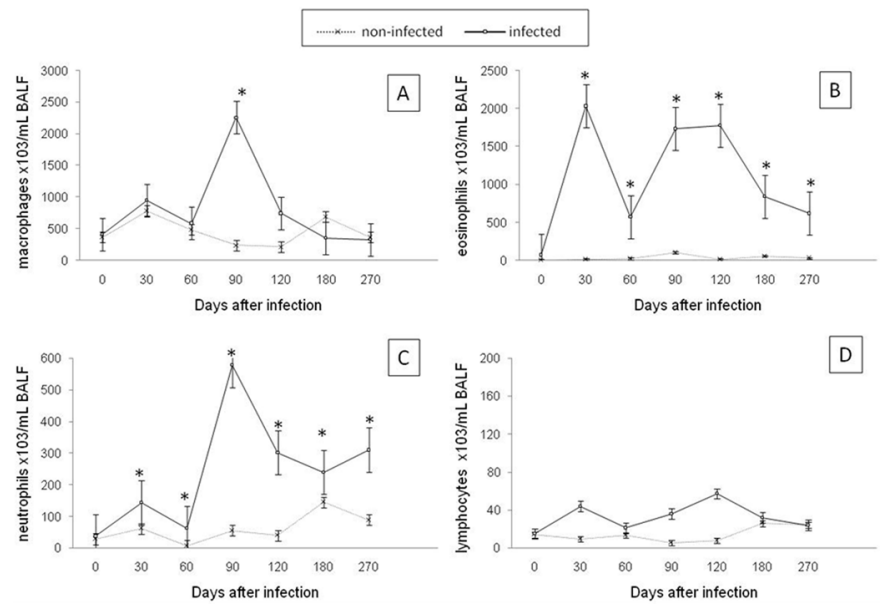

Fig.4. Differential cell count of the bronchoalveolar lavage fluid of the 14 cats infected with 800 infective larvae of Aelurostrongylus abstrusus per kilogram of body weight and from five non-infected cats lined as a control group. Absolute cell count expressed as: (A) macrophages $\times 10^{3} / \mathrm{mL}$ of bronchoalveolar fluid; (B) eosinophils $\times 10^{3} / \mathrm{mL}$ of bronchoalveolar fluid; (C) neutrophils $\times 10^{3} / \mathrm{mL}$ of bronchoalveolar fluid; (D) lymphocytes $\times 10^{3} / \mathrm{mL}$ of bronchoalveolar fluid. The asterisk indicates a significant statistical difference $(p<0.05)$.

-infected animals (Fig.4A). Multinucleated giant cells were also identified.

Eosinophils comprised the vast majority of cells from 30 to 270 DPI (Fig.4B). The nucleus of some eosinophils was lobed and the cells therefore resembled circulating eosinophils of peripheral blood. However, the nucleus in many eosinophils was spherical or ovoid and was eccentrically located. From 30 to 270 DPI, absolute counts in the infected animals revealed a significantly greater number of eosinophils in comparison to the non-infected animals and normal values described in current literature (Fig.4B).

Neutrophils were well preserved and morphologically similar to those in peripheral blood. The cytoplasm was clear to slightly granular. From 30 to $270 \mathrm{DPI}$, the absolute number of neutrophils was significantly elevated in the animals in the infected group ( $\mathrm{p}<0.05)($ Fig.4C). Absolute counts of infected animals revealed no significant differences in lymphocyte counts in the non-infected animals at the different evaluation times ( $p>0.05$ ) (Fig.4D).

\section{DISCUSSION}

In general, bronchoalveolar lavage in healthy animals resulted in minimal, transient effects on cardiopulmonary function. No important clinical signs were observed following the lavage procedures, beyond cough and moist crackling upon auscultation, which cleared up spontaneously within $24 \mathrm{~h}$. These results are in agreement with previous findings regarding bronchoalveolar lavage performed on healthy animals (McCauley et al. 1998, Basso et al. 2008, Hawkins et al. 2008). Nonetheless, oxygen therapy was employed in the present study before and after lavage due to the transient drop in oxygen saturation.

The cytological findings in the non-infected cats were generally consistent with those reported in previous studies (McCarthy \& Quinn 1989, Lécuyer et al. 1995), with variability possibly due to variations in technique, differences in sample size and the inclusion in some reports of epithelial cells in the differential cytology. Compared with transtracheal or transthoracic lung aspiration, a far greater portion of the lung is sampled with the lavage technique, which increases the probability of obtaining a diagnosis. The foamy appearance of the BALF reflected the presence of a surfactant, indicating the lavage of deep portions of the lungs and the collection of representative cells from small airways and alveoli (Barçante et al. 2008). BALF is a safe diagnostic procedure that can be used on humans and other animals to obtain specimens that could represent a disease developing in the lungs, such as infection by Aelurostrongylus abstrusus in cats (Lécuyer et al. 1995, Barutzki \& Schaper 2013).

Although the Baermann technique is the most important method for the diagnosis of aelurostrongilosis in vivo, the procedures may lack sensitivity due to the fact that L1 shedding is not continuous (Ribeiro \& Lima 2001). In this series of experiments, BALF proved to be an auxiliary diagnostic method, providing additional information on aelurostrongylosis. While complementary exams, such as electrocardiographic, radiological and cardiac function exams, may be used to support the differential diagnosis and follow up the effects of the parasite, these exams cannot be used to obtain a definitive diagnosis. Although BAL should not be considered a stand-alone diagnostic tool, when BAL cellular analysis is applied according to standardized protocols and considered in the appropriate clinical setting and context of other information obtained from ancillary diagnostic testing, it may allow the clinician to consider a parasitary infection. Specially when eosinophils comprises the majority of cell type recovered in the BAL. BALF has proven to be a technique for both the follow up of cellular changes in situ and confirmation of the definitive parasitological diagnosis. On other hand, the occurrence of L1 was detected only in three of the 14 infected animals, and 
just from 60 to $120 \mathrm{dpi}$. These results suggest that although BALF has a high especificity as a parasitological diagnosis method, it has sensitivity lower than other techniques. In the present study, eosinophils comprised the vast majority of cells 30 days after infection. In previous studies, eosinophilia is reported to be a key factor in many helminthic infections (Silveira-Lemos et al. 2006, Barçante et al. 2008).

Among infectious agents, helminth parasites are regarded as master manipulators of the host immune system, often inducing a long-lasting asymptomatic form of infection. Parasitic worms can establish and reproduce in mammalian hosts by switching off the inflammatory immune response and inducing a tolerant response to parasite antigens. The duration and intensity of the inflammatory agent determine different degrees or phases of transformation in tissues (Zaccone et al. 2006). The different $A$. abstrusus stages (adults, eggs and larva) cause different damage to the lung parenchyma (Scott 1972). In particular, egg production and larval migration trigger an intense inflammatory response, with bronchointerstitial pneumonia and lesions in the alveoli, bronchioles and arteries (Naylor et al. 1984).

The cellular analyses of BALF from infected cats in the acute phase of aelurostrongylosis shows an increase in the number of polymorphonuclear cells. Increased absolute cell counts of neutrophils were noted in the infected cats at 30 DPI and persisted through to the end of the observation period. Therefore, eosinophil and neutrophil influx in the lungs of infected cats may be correlated with the biology of the lifecycle of the parasite involved. The first peak at 30 DPI corresponded to the adult stage and initial oviposition. The increased cell count beginning at this time could be related to the amount of larvae passing from the lungs to the gut. Furthermore, larval growth and its secretion and excretion products are known to induce an increase in pulmonary cellularity. In this context, transendothelial migration is essential to eosinophil recruitment from blood vessels into inflammated tissues. At the site of inflammation, further interaction with invading parasites occurs via adherence with subsequent larval damage mediated by the release of effector molecules from the toxic granules of eosinophils (Silveira-Lemos et al. 2006).

Studies on immunological interactions between eosinophils and helminthic parasites have made important advances in understanding the innate role of eosinophils in controlling the eosinophil-associated tissue inflammation involved in infection by tissue migratory helminthic parasites (Shin et al. 2009). These regulatory mechanisms may also affect the immune response to other antigens by causing the polarization of the response. The identification of regulatory mechanisms has helped develop new models for understanding helminth infections, which remain among the most prevalent chronic diseases in the world. A number of studies have found that helminths can down regulate a range of immunopathological conditions, with the regulatory $\mathrm{T}$ cell one of the most common mechanisms in play (Fallon \& Mangan 2007, Maizels \& Yazdanbakhsh 2008). Inflammation involves a set of complex interactions between soluble factors and cells that can appear in any tissue during traumatic, infectious, post-ischemic, toxic or auto- -immune injuries (Nathan 2002). This process represents an adaptation to the loss of cell and tissue homeostasis and has important physiological functions, such as the defense of the host organism, tissue remodeling and repair and the regulation of the metabolism controlled by the transcription of genes (Medzhitov 2008, Medzhitov \& Horng 2009).

Th2 cells are involved in the differentiation and proliferation of $\mathrm{B}$ lymphocytes, the production of antibodies and the activation of cells of the innate immune system. Therefore, eosinophils found in sub-acute inflammation caused by helminths are important cells in the inflammatory response mediated by Th2 cells. Neutrophils exhibit a high potential for diapedesis, fast migration to the infection site and phagocytic action and can cause tissue necrosis due to the release of lysosomal enzymes in the interstitium.

Infection with helminthic parasites induces immune effector responses, which are characterized by IgE antibody production, tissue and peripheral blood eosinophilia and the participation of inflammatory mediator-rich tissue mast cells (Klion \& Nutman 2004). Although these types of responses can certainly induce pathologic reactions to parasitic infection, they have also been implicated in mediating protective immunity to helminthic parasites.

In the present study the authors demonstrated that cellular BALF evaluation provides useful information to the veterinary clinician, especially when larvae of $A$. abstrusus are found, enabling differentiate the illness from other pulmonary feline disease. The number of total leukocytes in the BALF of infected animals was significantly higher in comparison to non-infected animals. Furthermore, the study showed that alveolar macrophages and eosinophils represent the majority of BALF cells following infection. Studies on interactions between eosinophils and helminthic parasites have made important advances in clinical evaluation of infected animals. The great number of recovered eosinophilis during A. abstrusus infection in cats can helps the clinician in the elucidation of the parasitic infection. The BALF allows us to retrieve cells and first stage larvae which provide additional information about the inflammatory process caused by aelurostrongylosis. However, is important to continue this study to evaluate the presence of other elements as immunoglobulin and cellular markers that could provide more useful tools to the diagnostic and prognostic of feline aelurostrongylosis.

Acknowledgements.- The work was partially supported by FAPEMIG and CNPq-Brazil. The authors wish to thank Eduardo Luiz de Oliveira, Hudson Andrade dos Santos and Edna Maia for technical assistance.

\section{REFERENCES}

Barçante J.M., Barçante T.A., Ribeiro V.M., Oliveira-Jr S.D., Dias S.R.C., Negrão-Corrêa D. \& Lima W.S. 2008. Cytological and parasitological analysis of bronchoalveolar lavage fluid for the diagnosis of Angiostrongylus vasorum infection in dogs, Vet. Parasitol. 158:93-102.

Barçante J.M.P., Barçante T.A., Dias S.R.C., Vieira L.Q., Lima W.S. \& Negrão-Corrêa D.A. 2003. A method to obtain Angiostrongylus vasorum first-stage larvae from dog feces. Parasitol. Res. 89:89-93.

Barçante J.M.P. 2004. Aspectos clínicos, parasitológicos e imunológicos de cães experimentalmente infectados por Angiostrongylus vasorum. Revta Bras. Parasitol. Vet. 13:96-99. 
Barutzki D. \& Schaper R. 2013. Occurrence and regional distribution of $A e-$ lurostrongylus abstrusus in cats in Germany. Parasitol. Res. 112:855-861.

Basso P.C., Barcellos H.H.A., Brun M.V., Rodrigues L.B., Bortolini C.E., Melatti L., Neto J.F.S., Bastiani P.V., Valle S.F. \& Santos L.R. 2008. Tracheobronchic washing in dogs by means of rigid endoscopy or endotracheal tube. Ciência Rural 38:723-728.

Clercx C. \& Peeters D. 2007. Canine eosinophilic bronchopneumopath., Vet. Clin. North Am., Small Anim. Pract. 37:917-935.

Dürr B. 2009. Fein nadel aspiration der Lunge bei zwei Katzen mit Aelurostrongylus abstrusus-Infektion. Kleintierpraxis 54:88-92.

Fallon P.G. \& Mangan N.E. 2007. Suppression of TH2-type allergic reactions by helminth infection. Nature Rev. 7:220-230.

Gathumbi P.K., Waruiru R.M. \& Buoro I. 1991. A case of feline Aelurostrongylus abstrusus infection in Kenya. Bull. Anim. Hlth Prod. Afr. 39:361-363.

Hawkins E.C. 1992. Diagnostic tests for the lower respiratory tract, p.185. In: Nelson R.W. \& Couto G.C. (Eds), Essentials of Small Animal Internal Medicine. Mosby, Philadelphia. 185p.

Hawkins E.C., DeNicola D.B. \& Kuehn N.F. 2008. Bronchoalveolar lavage in the evaluation of pulmonary disease in the dog and cat. J. Vet. Intern. Med. 4:267-274.

Klion A.D. \& Nutman T.B. 2004. The role of eosinophil in host defense against helminth parasites. J. Allergy Clin. Immunol. 113:30-37.

Knaus M., Kusi I., Rapti D., Xhaxhiu D., Winter R., Visser M. \& Rehbein S. 2011. Endoparasites of cats from the Tirana area and the first report on Aelurostrongylus abstrusus (Railliet, 1898) in Albania. Wien. Klin. Wochenschr. 123:31-35.

Lacorcia L., Gasser R.B., Anderson G.A. \& Beveridge I. 2009. Comparison of bronchoalveolar lavage fluid examination and other diagnostic techniques with the Baermann technique for detection of naturally occurring Aelurostrongylus abstrusus infection in cats. J. Am. Vet. Med. Assoc. 235: 43-49.

Lécuyer M., Dubé P.G., Difruscia R., Desnoyers M. \& Lagacé A. 1995. Bronchoalveolar lavage in normal cats. Can. Vet. J. 36:771-773.

Lima W.S., Costa H.M.A., Guimarães M.P. \& Leite A.C.R. 1985. Angiostrongylus vasorum (Baillet, 1866) Nematoda: Prothostrongylidae em cães de Minas Gerais, Brasil. Mem. Inst. Oswaldo Cruz 80:233-235.

Losonsky J.M., Thrall D.E. \& Prestwood A.K. 1983. Radiographic evaluation of pulmonary abnormalities after Aelurostrongylus abstrusus inoculation in cats. Am. J. Vet. Res. 44:478-482.

Maizels R.M. \& Yazdanbakhsh M. 2008. T-cell regulation in helminth parasite infections: implications for inflammatory diseases. Chem. Immunol. Allergy 94:112-123.

McCarthy G.M. \& Quinn P.J. 1989. Bronchoalveolar lavage in the cat: cytologic findings. Can. J. Vet. Res. 53:259-263.

McCauley M., Atwel R.B., Sutton R.H. \& Lumsden J.S. 1998. Unguided bron- choalveolar lavage techniques and residual effects in dogs. Aust. Vet. J. 76:161-165.

Medzhitov R. 2008. Origin and physiological roles of inflammation. Nature 454:428-435.

Medzhitov R. \& Horng T. 2009. Transcriptional control of the inflammatory response. Nature Rev. 9:692-703.

Nathan C. 2002. Points of control in inflammation. Nature 420:846-852.

Naylor J.R., Hamilton J.M. \& Weathereley A.J. 1984. Changes in the ultrastructure of feline pulmonary arteries following in infection with the lungworm Aelurostrongylus abstrusus. Brit. Vet. J. 140:181-190.

Payo-Puente P., Diez A., Gonzalo-Orden J.M., Notomi M.K., Rodríguez-Altónaga J.A., Rojo-Vázquez F.A. \& Orden A.M. 2005. Computed Tomography in cats infected by Aelurostrongylus abstrusus: 2 clinic cases. Intern. J. Appl. Res. Vet. Med. 3:339-343.

Pennisi M.G., Niutta P.P. \& Giannetto S. 1994. Parásitos pulmonares em el gato. Med. Vet. 11:568-572.

Ribeiro V.M. \& Lima W.S. 2001. Larval production of cats infected and re-infected with Aelurostrongylus abstrusus (Nematoda: Protostrongylidae). Revue Méd. Vét. 152:815-829.

Scott D.W. 1972. Current knowledge of Aelurostrongylus abstrusus in the cat. Cornell Vet. 63:483-500.

Shin M.H., Lee Y.A. \& Min D. 2009. Eosinophil-mediated tissue inflammatory responses in helminth infection. Korean J. Parasitol. 47:125-131.

Silveira-Lemos D., Teixeira-Carvalho A., Martins-Filho O.A., Oliveira L.F.A. \& Corrêa-Oliveira R. 2006. High expression of co-stimulatory and adhesion molecules are observed on eosinophils during human Schistosoma mansoni infection. Mem. Inst. Oswaldo Cruz 101:345-351.

Soulsby E.J. 1987. Parasitología y Enfermedades Parasitarias en Animales Domésticos. Interamericana, México. 280p.

Traversa D. \& Guglielmini C. 2008. Feline aelurostrongylosis and canine angiostrongylosis: a challenging diagnosis for two emerging verminous pneumonia infections. Vet. Parasitol. 157:163-174.

Traversa D., Iorio R. \& Otranto D. 2008a. Diagnostic and clinical implications of a nested PCR specific for ribosomal DNA of the feline lungworm Aelurostrongylus abstrusus (Nematoda, Strongylida). J. Clin. Microbiol. 46:1811-1817.

Traversa D., Lia R.P., Iorio R., Boari A., Paradies P., Capelli G., Avolio S. \& Otranto D. 2008b. Diagnosis and risk factors of Aelurostrongylus abstrusus (Nematoda, Strongylida) infection in cats from Italy. Vet. Parasitol. 153:182-186.

Willard M.D., Tvedten H. \& Turnwald G.H. 1988. Small animal Clinical Diagnosis by Laboratory Methods. W.B. Saunders Company, Philadelphia, p.53-79.

Zaccone P., Fehervari Z., Phillips J.M., Dunne D.W. \& Cooke A. 2006.Parasitic worms and inflammatory diseases. Parasite Immunol. 28:515-523. 